\title{
Self-leadership and Work Role Innovation: Testing a Mediation Model with Goal Orientation and Work Motivation
}

\section{Autoliderazgo y Motivación de Rol Laboral: Prueba de un Modelo de Mediación con Orientación de Meta y Orientación Laboral}

\author{
Luis Curral and Pedro Marques-Quinteiro \\ University of Lisbon, Lisbon, Portugal
}

\begin{abstract}
This article explores the relationship between self-leadership, goal orientation, intrinsic motivation, and innovative behavior. Because innovation requires self-navigation competences we propose that self-leadership skills mediate the relationship between goal orientation and role innovation, as well as between intrinsic motivation and role innovation. To investigate this, 108 employees from three companies, working on the development and implementation of technological solutions, were surveyed on their goal orientation believes, their level of intrinsic motivation, their self-leadership strategies, and the frequency they introduce new procedures on their jobs. Structural equation modelling showed a positive relationship with role innovation for learning goal orientation and intrinsic motivation, but not for performance goal orientation. Self-leadership skills fully mediated the relationship between learning goal orientation and role innovation and partially mediated the relationship between intrinsic motivation and role innovation. Thus, enhancing employees' self-navigation competences might be an avenue for enhancing their innovative behavior.

Key words: self-leadership, goal orientation, motivation, work role innovation.

Resumen. Este artículo explora la relación entre el autoliderazgo, la orientación de meta, la motivación intrínseca y la conducta innovadora. Debido a que la innovación requiere competencias de autonavegación, proponemos que las destrezas de auto-liderazgo median la relación entre la orientación de meta y la innovación de rol, así como entre la motivación intrínseca y la motivación de rol. Para investigar esto, 108 empleados de tres compañías dedicadas al desarrollo e implementación de soluciones tecnológicas fueron encuestados en sus creencias de orientación de meta, su nivel de motivación intrínseca, sus estrategias de autoliderazgo y la frecuencia con la que introducen nuevos procedimientos en sus trabajos. Un modelo de ecuaciones estructurales mostró una relación positiva con la innovación de rol para el aprendizaje de la orientación de meta y la motivación intrínseca pero no para el desempeño de la orientación de meta. Las destrezas de autoliderazgo mediaron completamente entre la motivación intrínseca y la innovación de rol. De este modo, facilitar las competencias de autonavegación de los empleados podría ser un camino para facilitar la conducta innovadora.

Palabras clave: autoliderazgo, orientación de meta, motivación, innovación de rol laboral.
\end{abstract}

Through change and chaos, leadership has become the most challenging and complex process in work and organizational environments (Litchtenstein, Uhl-Bien, Marion, Seers, Orton \& Schreiber, 2006). Today organizations are no longer in need of great leaders and managers. In fact, as the environment becomes more unpredictable, what they need is extraordinary leaders capable of leading others to lead them selves by developing the necessary competences and motivations that allow for innovative and high performing organizations and teams (Judge \& Piccolo, 2004; Manz \& Neck, 2004; Vargas, 2007).

Luis Curral and Pedro Marques-Quinteiro, Faculdade de Psicologia, Universidade de Lisboa. Correspondence about this article should be sent to Luis Curral, Psicología Organizacional, Faculdade Psicología, Universidade de Lisboa, Alameda da Universidade, 1649-013 Lisboa, Portugal.

\section{Self Leadership: A theoretical definition}

Presented by Manz (1986), self-leadership is a psychological construct that represents one's capacity for performance enhancement, through a repertoire of ongoing cognitive, motivational and behavioural selfnavigation strategies (Manz \& Neck, 2004; Neck \& Houghton, 2006). Being either a trait or a pre-disposition, self-leadership is a competence for leading oneself across challenging and performing situations that precede goal achievement and request goal setting and goal striving (Gollwitzer, 2003; Gollwitzer, Heckhausen \& Steller, 1990; Manz \& Neck, 2004; Neck \& Houghton, 2006).

Since it was first presented by Manz, self-leadership theory has always been criticized due to its apparent similarities with many other theories and variables (Neck \& Houghton, 2006). Several authors 
argue that the proposed self-navigation mechanisms energized through cognitive and behavioural strategies are nothing more and nothing less than a reshape of already known variables such as consciousness, proactive personality or self-regulation (Neck \& Houghton, 2006). However, what is not being considered is the fact that self-leadership is neither a trait nor a descriptive theory (Manz \& Neck, 2004; Neck $\&$ Houghton, 2006). Instead, it is a normative or prescriptive theory that states how already known traits, motivations and self regulation processes should operate in order to provide individual maximum performance (Manz \& Neck, 2004; Neck \& Houghton, 2006). Considering personality, for example, some studies have found a relation between self-leadership and personality traits such as the Big 5 and the Myers-Briggs Type Indicator (Houghton, Bonham, Neck, \& Singh, 2004; Manz \& Neck, 2004; Stewart, Carson, \& Cardy, 1996; Wi-lliams, Verble, Price, \& Layne, 1995). However, this relation as proved not to be interactive or dependent (Houghton et al., 2004). Besides, self-leadership is conceptualized as a learned behaviour, being sensible to training opportunities and change (Manz, 1986), while motivational and personality traits are not (Costa \& McCrae, 1988). This leads to the idea that they are distinct and independent constructs that might coexist and relate through the impact on a common outcome (Neck \& Houghton, 2006).

Self-leadership has a broad spectrum of theoretical origins influencing its definition and the way it is seen as an individual and team performance energizer. Instead of suggesting discontinuation, self-leadership builds on self-management (Manz \& Sims, 1980), self-regulation (Carver \& Scheier, 1981, 1998), socio-cognitive (Bandura, 1986) and motivational theories (Deci \& Ryan, 1985; Manz \& Neck, 2004; Neck \& Houghton, 2006), integrating them in a complete set of behavioural and cognitive strategies. Thus, from a self regulation perspective, self-leadership strategies allow for the increase of self regulation processes through the refining of internal focus mechanisms, goal management, feedback strategies and task performance outputs (Neck \& Houghton, 2006). From a social-cognitive perspective, self-leadership strategies help to improve self-efficacy perceptions and refine regulation processes, having significant impact on individual task performance (Houghton \& Neck, 2006). From a self-management perspective, self-leadership builds on goal management strategies, explaining the how and why. Although they share a focus on behavioural focused strategies and natural reward strategies (Manz, 1986), self-leadership refines self-management processes by suggesting the existence of cognitive and motivational issues leading to a third kind of strategy named constructive though pattern strategies (Neck \& Manz, 1992; Neck \& Houghton, 2006).

\section{Behavior focused strategies}

Behavior focused strategies are about enhancing one's self perception of personal performance during task resolution, in order to adjust self behaviour towards task achievement. Through self observation, self setting of goals and objectives; self reward administration; self punishment and self cueing it maximizes behaviour effectiveness and helps reducing negative issues related with the task (Houghton \& Neck, 2002; Manz \& Neck, 2004; Neck \& Houghton, 2006). Self-observation stands for one's self consciousness and reflection concerning why and how specific behaviours impact individual, team or organizational performance, leading individuals to suppress or promote such behaviours (Neck \& Houghton, 2006). Selfsetting of targets and goals concerns the set of behaviours that promote the adjustment of individual targets and goals towards current performance in order to achieve desired outcomes (Neck \& Houghton, 2006). Self-reward strategies work as a performance energizer that looks either to promote or to inhibit performance behaviours through intangible or material rewards such as a self mental congratulation or a weekend on the mountains (Neck \& Houghton, 2006). Self-punishment includes negative feedback mechanisms that strive to guide personal behaviours towards desired goals by reducing undesired or ineffective behaviours. However, it might happen that these strategies lead to somehow less adaptable strategies and consequences (Neck \& Houghton, 2006). Self-Cueing is all about an individual coming up with personal guidance strategies that allow him not to forget targets and goals and to achieve desired performance levels (e.g. post it's; screen savers messages) (Neck \& Houghton, 2006).

\section{Natural self reward strategies}

This strategies concern self search and the promotion of pleasant and enjoyable feelings directly related to the task, intended to energize task oriented behaviours that enhance performance through task positive modelling and suppression of task negative issues (Houghton \& Neck, 2002; Manz \& Neck, 2004; Manz \& Sims, 2001; Neck \& Houghton, 2006). Task positive modelling is a strategy that tries to change the job related features in order to make them more appealing to the individual, rendering the task more enjoyable (Neck \& Houghton, 2006). Suppression of task negative issues can be thought of as an avoiding strategy because it directs one's attention only to the positive aspects of the job while neglecting the negative ones (Neck \& Houghton, 2006).

\section{Constructive though pattern strategies}

These are the strategies that better distinguish self- 
leadership from other competing concepts (e.g. selfregulation, self-management). Through the evaluation of one's values and beliefs, self-talk and self mental imagery individuals develop and facilitate more constructive and adaptable though patterns, minimizing destructive and ineffective thinking (Houghton \& Neck 2002; Manz, 1986; Manz \& Neck 2004; Manz \& Sims 2001; Neck \& Houghton, 2006; Seligman, 1991). Evaluation of one's values and beliefs implies the self monitoring of how personal values and beliefs are positively or negatively affecting performance and the necessary modifications that need to be done in order to adjust them to targets and goals, maximizing performance (Neck \& Houghton, 2006). Self-talk allows for the individual to mentally speak to himself and develop better reflecting thought patterns, in order to compare and understand the nature of the relationships between values, beliefs, targets and goals (Neck \& Houghton, 2006). Self mental imagery is a fundamental issue on the processes, because it leads to the mental testing of the hypothesis developed through the self talk process and their impact on performance (Neck \& Houghton, 2006).

\section{Self-Leadership: Antecedents and Consequents}

Self-leadership is a psychological construct naturally developed and acquired during personal and professional experience (Manz, 1986; Neck \& Manz, 1992). Research from Neck and Manz (1992) showed that individuals who received specific training in self-leadership competences (constructive though pattern strategies) reported higher performance, satisfaction and self-efficacy levels), when compared to those who did not receive such training. In another study Yun, Cox \& Sims Jr. (2006) showed that self-leadership skills development and effective occurrence was strongly dependent on leadership style. The authors found that co-workers' self-leadership behaviors would increase or decrease depending on empowerment and autonomy levels. These findings contributed for the belief that self-leadership is also an emergent state strongly dependent on contingent factors (Yun, Cox \& Sims Jr., 2006). Concerning this topic, there is at least one discordant finding. According to Konradt, Andreßen and Ellwart (2009), self-leadership impact on individual performance was partially mediated by self-efficacy perception, while autonomy and task characteristics showed no significant effects.

Self-leadership has also been considered in multicultural research. Giorgianna (2007) compared two samples of American and Chinese students, concerning their self-leadership levels. The author found that American students scored higher on self-leadership competences and skills than Chinese students. An earlier research conducted by Neubert and Wu (2006) found that the Revised Self-Leadership Questionnaire
(Houghton \& Neck, 2002) and the theoretical construct in itself (Manz, 1986; Manz \& Neck, 2004) are not suited for Chinese samples. Although, this same study also showed that self-leadership has a strong positive effect on creativity and work role performance. Carmeli, Meitar, and Weisberg, (2006) and DiLiello and Houghton (2006) have found that self-leadership is a strong predictor of innovation as perceived by coworkers and managers.

\section{Work role innovation}

Although there are several definitions of innovation, all of them distinguish it from creativity, agreeing on the same necessary processes and contingency issues for it to happen (Carmeli, et al., 2006; West, Shackleton, Hardy \& Dawson, 2001). While creativity concerns the happening and development of an idea with some usefulness potential (Amabile, 1988; DiLiello \& Houghton, 2006; Phelan \& Young, 2003; Shalley, Zhou \& Oldham, 2004), work role innovation requires the full materialization of the creative thought, through the development and effective application of significant and improving changes on the normal procedures concerning role and tasks (West et al., 2001). Besides, it also has to significantly impact and change the environment in which it occurs (Curral, 2005; Van de Ven, 1986; West et al., 2001).

As a complex behavioural, affective and cognitive process (Scott \& Bruce, 1994), innovation requires (a) the identification and definition of a problem, followed by the generation of creative solutions, (b) active search and gathering of resources (human and non human) for idea support and validation and $(c)$ the presentation, testing and validation of the model or project developed (Carmeli et al., 2006; Kanfer, 1988). All of this depends on the existence of self-navigation skills, ones that only exist through self-leadership (Carmeli et al., 2006; Latham \& Locke, 1991; Manz, 1986; Manz \& Neck, 1999). In fact, besides the obvious necessity of a supporting environment for innovation (Amabile, 1988; West et al., 2001), it is also necessary that the individual possess self guidance and navigation competences that allow him to navigate through challenges and frustrations, usually associated with (1) problem identification and situational constraints, (2) generation of new ideas and solutions, (3) gaining the trust of those taking part in the process and (4) the successful implementation of the innovative idea (Carmeli et al., 2006; Scott \& Bruce, 1994).

Concerning the relation between self-leadership and innovation, Phelan and Young (2003) have given a significant theoretical contribution by presenting the concept of creative self-leadership. According to the authors, it stands for the conscious cognitive processes of reflection and ideas generation directed towards desired improvements and changes in the environment 
(Carmeli et al., 2006; Phelan \& Young, 2003). This new concept considers innovation as being dependent on the occurrence of the following phenomenon's $(a)$ active and ongoing transformation of cognitive structures and mental repertoires (e.g. values and beliefs), (b) the occurrence of imagery processes that create doubt and force individual to think, allowing for ideas testing, experimentation and transformation, and $(c)$ self talk behaviours that stimulate internal questioning, arguing and feedback (Carmeli et al., 2006; Phelan \& Young, 2003). Unfortunately, Phelan and Young conclusions were only theoretical.

DiLiello and Houghton (2006) conducted an empirical research relating self-leadership, innovation and creativity. The results revealed that co-workers scoring high on self-leadership considered themselves to be more innovative and creative, when compared to those scoring lower. This study also demonstrated that, in the presence of a strong organizational support for innovation, higher self-leadership individuals demonstrated more creative and innovative practices, compared to those who scored lower on self-leadership (DiLiello \& Houghton, 2006).

Considering self-navigation cognitive and behavioural competences and the conclusions advanced by Phelan and Young (2003), DiLiello and Houghton (2006), Carmeli et al. (2006), and Neck and Houghton (2006), the following hypothesis is proposed:

\section{H1: Self-leadership will have a positive relationship} with work role innovation.

\section{Goal orientation}

Work motivation can be understood as the cognitive and affective processes determining how personal efforts and resources are allocated to actions pertaining work roles. The regulatory mechanism behind these processes is called self-regulation; a mechanism on which self-leadership builds upon and that includes regulatory mechanisms for direction, intensity and persistence behaviours (Kanfer, Chen \& Pritchard, 2008; Mitchell \& Daniels, 2003). It varies within and across individuals and situations, and it is largely dependent on interactions between individual and environmental characteristics (Kanfer et al., 2008; Mitchell \& Daniels, 2003).

According to recent research, motivation is dependent on 3 psychological processes: arousal (the need or desire for some object or state that is at least partially unfulfilled or below expectation), direction (direction goals guiding one's behaviour) and intensity (the strength of one's desire and need to achieve goals and needs with different difficulty levels) (Bandura, 1986; Ford, 1992, Kanfer, 1990). In fact, all of these psychological processes depend on personal needs, values and beliefs (Latham, 2007).
Dweck's Goal Orientation Theory represents how personal goals and beliefs create the mental framework from which individuals follow avoidance or approach strategies towards goals, being a distinct construct from both goal setting (e.g. personal choices concerning most attractive goals) and goal striving (e.g. behaviors and thoughts directed towards a specific goal) (Dweck, 1986; Dweck \& Legget, 1988; VandeWalle \& Cummings, 1997). Goal orientation relies on personal beliefs concerning intelligence as either incremental (e.g. learning orientation) or stable (e.g. performing orientation), arguing that these beliefs are responsible for the way individuals apply specific strategies towards the pursuit of goals. Although first theorists considered goal orientation as a single construct aligned in a continuum. (Button, Mathieu \& Zajac, 1996; Chen \& Mathieu, 2008; Dweck, 1986; Latham, 2007; VandeWalle, Cron \& Slocum, 1999), later research revealed that both learning orientation (the belief that personal competences, skills and intelligence can be developed) and performance orientation (the belief that personal competences, skills and intelligence can not be improved) are independent traits (Button et al., 1996; WandValle et al., 1999). Even more, performance orientation has shown to possess an avoidance dimension (avoiding failure and to show incompetence) and a performing dimension (choosing to perform easier tasks in order to succeed, showing competence) towards the pursuit of results (Button et al., 1996; Chen \& Mathieu, 2008; WandValle et al., 1999). Another curious finding is that, concerning performance orientation, high learning oriented individuals can have a moderate positive level of performance orientation towards the achieving dimension, while the avoidance dimension has strong negative correlation with both learning and performance achieving orientations (Chen \& Mathieu, 2008; WandValle et al., 1999).

Learning oriented individuals are known to apply more adaptable strategies towards the mastery of goals and challenges, being particularly motivated to engage in increasing complex, challenging and enjoyable tasks that might allow them to learn and develop new skills and competences (Button et al., 1996; Chen \& Mathieu, 2008; Latham, 2007; LePine, 2005; VandeWalle et al., 1999). Learning oriented individuals are also known to be more optimistically and opened to experience, willing to be effortful and to perform challenging tasks (LePine, 2005; VandeWalle et al., 1997; VandeWalle et al., 1999), to possess an internal locus of control (Button et al., 1996) and to obtain higher levels of sales performance when using self regulation strategies activated through emotional arousal and negative feedback (e.g. goal setting, effort and planning) (VandeWalle et al., 1999).

On the contrary, performance oriented individuals are known to engage in non-adaptable behaviours, reporting higher levels of stress and poorer performance when in complex and challenging tasks (Button 
et al., 1996; LePine, 2005; VandeWalle et al., 1997; VandeWalle et al., 1999). However, research as shown that when performing simple tasks, performance oriented individuals can achieve higher performance levels, when compared to learning oriented ones (Button et al., 1996; LePine, 2005; VandeWalle et al., 1997; VandeWalle et al., 1999). This might happen because of the enhancement of self-efficacy perception and the development of positive feelings towards the task.

Considering what has been said till now and knowing that a) innovation requires adaptable and proactive behaviours (Curral, 2005; West et al., 2001), goal orientation impacts creativity (Hirst, van Knippenberg \& Zhou, 2009) and that values and beliefs only impact performance when attached with strong behavioural and cognitive structures and dispositions (Smith \& Terry, 2003; Snyder \& Swan, 1976):

H2. Learning orientation will have a positive relationship with work role innovation, and this relationship will be mediated by self-lea-dership. That is, learning orientation will be associated with a greater use of self-leadership strategies, which in turn will be positively associated with role innovation.

H3: Performance orientation will have a negative relationship with work role innovation and this relationship will be mediated by self-leadership. That is, performance orientation will be associated with less use of self-leadership strategies, which in turn will be positively associated with role innovation.

\section{Intrinsic motivation}

As already said, innovation is preceded by creative thoughts that share with self-leadership the dependence on motivation (Amabile, 1997; Carmeli et al., 2006; Deci \& Ryan, 1985). Motivation can be defined as a set of cognitive processes through which individual determine the amount of time and effort they will invest on the pursuit of specify needs and goals. Depending on its origins, motivational processes can be either intrinsic or extrinsic (Deci \& Ryan, 1985).

With an internal source, intrinsic motivation is all about the desire to enjoy performing a task by its nature, being well known to be positively related to higher autonomy levels, self-efficacy perception and work performance satisfaction (Deci \& Ryan, 1985; Dysvik \& Kuvväs, 2008; Kuvväs, 2006). This is why it is considered to precede self-leadership (DiLiello \& Houghton, 2006). Although only exists theoretical propositions, intrinsic motivation is considered to be one of the main explanatory variables concerning selfleadership mechanisms, especially behaviour focused strategies and natural reward strategies (Neck \& Houghton, 2006).

Taking a closer look at Deci and Ryan's (1985)
Cognitive Evaluation Theory, it is easy to see that competence needs and self determination are the fundamental mechanisms that promote intrinsic motivation and lead to active strategies of problem resolution, resulting in higher levels of positive feelings, performance, innovation, creativity and satisfaction (Amabile, 1997; Carmeli et al. 2006; DiLiello \& Houghton, 2006; Neck \& Houghton, 2006; Pattal, Cooper \& Robinson, 2008).

Considering this and reminding self-leadership navigation properties, it is hypothesised that:

H4: Intrinsic motivation will be positively related to work role innovation and this relationship will be mediated by self-leadership. That is, learning orientation will be associated with greater use of self-leadership strategies, which in turn will be positively associated with role innovation.

\section{Method}

\section{Participants and procedure}

The study took place in three international companies in Portugal, working on the development and implementation of software products and solutions. Within each company, in cooperation with the HR director, all employees with technological jobs were invited by email to participate in the study. The questionnaire fulfilment took approximately 15 minutes and was done on a paper and pencil format. Questionnaires were handled to and collected from the participants personally by the researchers.

By the end of application, 108 employees participated in this study. Approximately the same amount of participants came from each company. Respondents' average age was 38 years ( $\mathrm{SD}=9.8$ years), the average job experience was 8 year ( $\mathrm{SD}=6$ years), and $53 \%$ were male. Almost $93 \%$ of the participants held at least one academic degree, and only $14 \%$ held a supervisor position.

\section{Measures}

All measures used were adapted and translated to the Portuguese language through back translation techniques and language expert supervision. In order to assure minimal quality standards for measures reliability a pilot study with 30 participants, with at least 6 months of professional experience and a mean age of 22 , was conducted.

Self-leadership. Twenty four items, from the Revised Self-Leadership Questionnaire (Houghton \& Neck, 2002) were used to assess participants' selfleadership skills. To shorten the application process only the 3 items with higher loadings in each dimen- 
Figure 1. Relations between performance orientation, learning orientation, intrinsic motivation, self-leadership and work role innovation: The hypothesized model

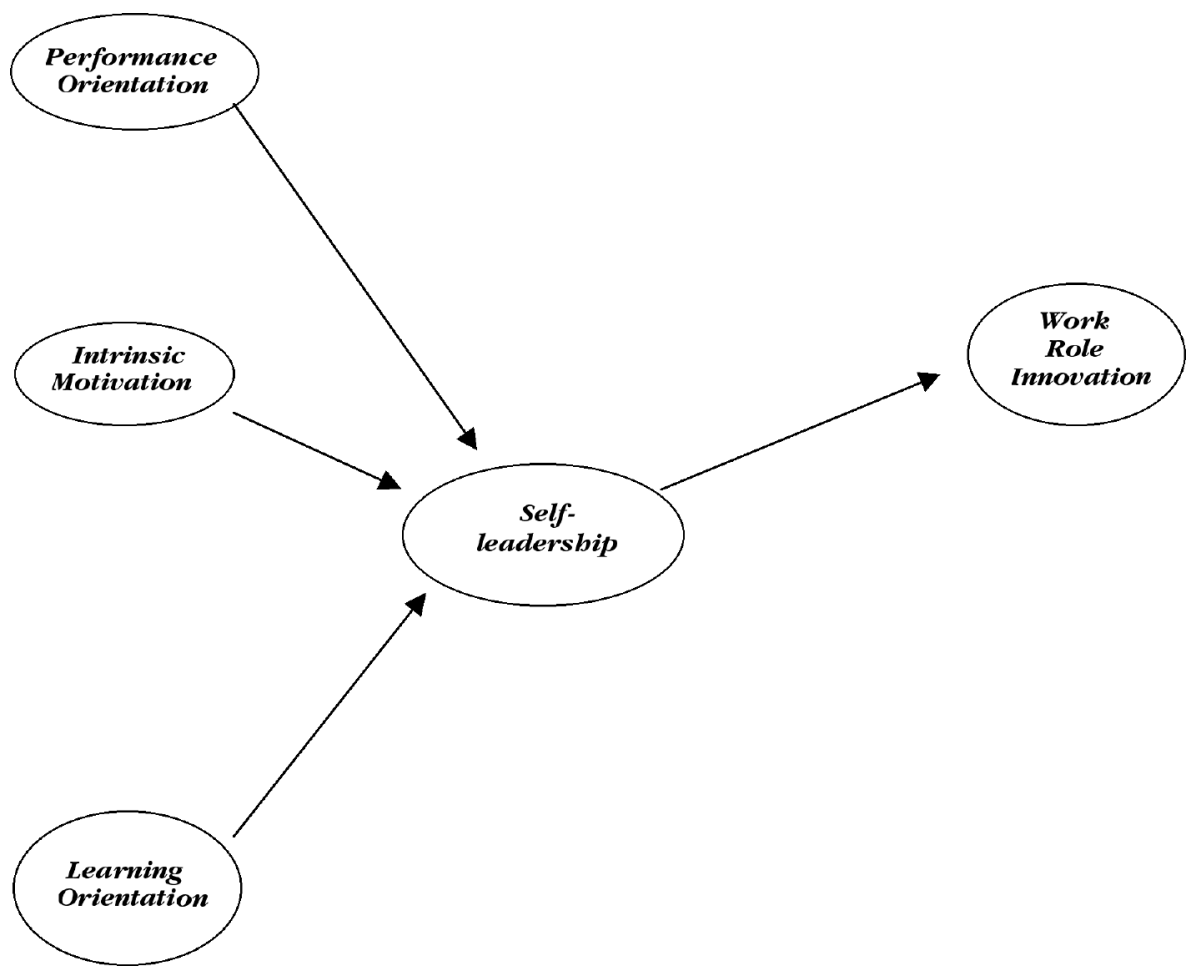

sion were kept (see Houghton \& Neck, 2002). Also by authors suggestion the self-punishment dimension was not included. A principal component analysis with oblimin rotation was performed on the 24 items. All items loaded above .50 on the correspondent factors.

(A) Behaviour focused strategies include four dimensions: 1) Self-Goal Setting, a sample item is "I work toward specific goals I have set for my self" and its Cronbach alpha coefficient was .73;2) Self-Reward a sample item is "When I have successfully completed a task, I often reward my self with something I like" and the Cronbach alpha coefficient was .94;3) SelfObservation, a sample item is "I pay attention to how well I am doing in my work", and the Cronbach alpha coefficient was .65; 4) Self-Cueing, a sample item is "I use written notes to remind my self of what I need to accomplish" and the Cronbach alpha coefficient was .91 .

(B) Natural reward strategies is a single dimension (3 items), a sample item is "I find my own favourite ways to get things done". The Cronbach alpha coefficient was .68.

(C) Constructive though pattern strategies include three dimensions: 1) Visualizing Successful Performance/Imagery, a sample item is "Sometimes I picture in my mind a successful performance before I actually do a task" and the Cronbach alpha coefficient was .72; 2) Self-talk, a sample item is "When I am in difficult situations, I will some times talk to my self (out loud or in my head) to help me get through it", its Cronbach alpha coefficient was .89 ; 3) Self-evaluation of one values and beliefs, a sample item was "I think about and evaluate the beliefs and assumptions I hold", and the Cronbach alpha coefficient was .86.

Answers to the Revised Self-Leadership Questionnaire were given on a 5-point scale ranging from $1=$ "totally disagree" to $5=$ "totally agree". The Cronbach alpha coefficient for the general self-leadership measure was .84 .

Goal Orientation was accessed with the 16-item version of Goal Orientation Scale (Button, Mathieu \& Zajac, 1996). A principal component analysis with oblimin rotation was performed on the sixteen items. All items loaded above .50 on the correspondent factors. A sample item of the 8-item learning goal orientation scale was "The opportunity to do challenging work is important to me". The Cronbach alpha coefficient was .81. A sample item of the 8-item performance goal orientation scale was "I feel smart when I do something better than most people". The Cronbach alpha coefficient was .82. Answers were given on a 5 -point scale ranging from $1=$ "totally disagree" to $5=$ "totally agree".

Intrinsic Motivation was measured with 5 items from a scale developed by Kuvväs (2006). Although the original version of the questionnaire had 6 items, 
the last one was removed for showing week reliability values ("I feel lucky for being paid for a job I like so much"). Answers were given on a 5-point scale ranging from $1=$ "totally disagree" to $5=$ "totally agree". The Cronbach alpha coefficient for the 5-item scale was .88 .

Work Role Innovation was assessed with the 5-item Work Role Innovation Scale (West et al., 2001). Participants were asked how often they had introduced any new procedure or process in their job in the last year. A sample item was "Did you introduced new ways to achieve your goals". Answers were given on a 5 -point scale ranging from $1=$ "rarely" to $5=$ "frequently". The Cronbach alpha coefficient was .87 .

Background measures. The questionnaire included the following background variables: gender $(0=$ male, $1=$ female), age, and professional experience in years.

\section{Results}

Table 1 shows the means, standard deviations, and correlations for the measures. Significant correlations were found between work role innovation and the general self-leadership dimension $(r=.37)$, learning orientation $(r=.27)$, and intrinsic motivation $(r=.32)$.

To test our hypothesized full mediation model we conducted a Structural Equations Modelling (SEM) analysis, which as the advantages of correcting for unreliability of measures and to test the relationship between antecedents (learning orientation, performance orientation, intrinsic motivation), mediator (selfleadership) and outcome (role innovation) simultaneously (MacKinnon, Fairchild \& Fritz, 2007).

We considered a model with five latent factors (selfleadership, work role innovation, intrinsic motivation, learning orientation, and performance orientation) and the respective items mentioned in the Method section as observed variables. For self-leadership we used the eight scales as observed variables in order to reduce the number of free parameters to estimate. According to Arbuckle (2005) with small samples it may be impractical to fit the saturated model because of the large number of parameters. Professional experience was included as a control variable in the model because it was the only background measure that correlated significantly with work role innovation. Evaluation of model fit was based on the following indices (Schmitt \& Branscombe, 2002): Chi-Square Index for Fit Quality $\left(\chi^{2}\right)$, which allows to estimate variance's real value; the Ratio value $\chi^{2} / \mathrm{df}$, a more secure indicator of the model fit quality (it gives the number of degrees of freedom related to $\chi^{2}$ ); root mean square approximated error (RMSEA); the comparative adjusted index (CFI), and the standardised root mean square residual (SRMS). Accordingly to $\mathrm{Hu}$ and Bentler (1999) the following values indicate a good fit of the model to the data: TLI and CFI to range from .95 to 1 , RMSEA below .06, SRMR below .09 , and $\chi^{2 / \mathrm{df}}$ between 1 and 2 .

The hypothesized model fit the data reasonably well with $\chi^{2}=471.43, \chi^{2} / d f=1.27$, RMSEA $=.05, \mathrm{CFI}=.92$, and SRMS=.09. Hypothesis 1 stated that self-leadership is positively relationship with role innovation. The results of the SEM analysis showed a significant positive relationship between self-leadership and participants ratings of work role innovation $(\beta=.50, p<$ $.01)$ thus bringing full support to our first hypothesis. The second hypothesis assumed that learning orientation would have a positive relationship with role innovation and that relationship would be fully mediated by self-leadership also received full support. The relationship between participants' learning goal orientation and self-leadership competences was positive and significant $(\beta=.48, p<.01)$. However, the full mediation of self-leadership between performance orientation and

Table 1. Means, standard deviations, and intercorrelations of main study variables

\begin{tabular}{|c|c|c|c|c|c|c|c|c|c|c|c|c|c|c|c|c|c|}
\hline & $M$ & $S . D$ & 1 & 2 & 3 & 4 & 5 & 6 & 7 & 8 & 9 & 10 & 11 & Gender & .58 & .49 & .12 \\
\hline Work experience & 8 & 6 & $.53 * *$ & $* .08$ & - & & & & & & & & & & & & \\
\hline Performance orientation & 3.89 & .75 & .04 & -.14 & $.22 *$ & - & & & & & & & & & & & \\
\hline Learning orientation & 4.52 & .43 & .02 & -.07 & .10 & .02 & - & & & & & & & & & & \\
\hline Intrinsic motivation & 3.94 & .73 & .09 & $.25 *$ & .17 & .02 & $.34 * *$ & - & & & & & & & & & \\
\hline Self-leadership & 3.36 & .45 & -.19 & -.01 & -.17 & .08 & $.24 *$ & .12 & - & & & & & & & & \\
\hline Self-goal setting & 4.00 & .59 & .02 & .08 & .09 & .01 & $.49 * *$ & $.26 * *$ & $.48 * *$ & - & & & & & & & \\
\hline Self-reward & 2.28 & .92 & -.12 & -.03 & -.08 & .06 & .04 & .06 & $.53 * *$ & .10 & - & & & & & & \\
\hline Self-observation & 3.70 & .64 & -.13 & .14 & -.12 & .05 & $.29 * *$ & $.26 * *$ & $.54 * *$ & $.52 * *$ & .14 & - & & & & & \\
\hline Self-cueing & 3.88 & .88 & -.09 & -.15 & -.06 & .05 & .18 & .11 & $.44 * *$ & $.28 * *$ & $.24 *$ & $.22 *$ & - & & & & \\
\hline Natural rewards & 3.85 & .59 & -.20 & .14 & -.22 & -.02 & $.21 *$ & .06 & $.41 * *$ & $.36^{* *}$ & .15 & $.37 * *$ & .08 & - & & & \\
\hline Visualization & 3.17 & .84 & -.02 & -.02 & -.08 & $.20 *$ & .09 & .03 & $.51 * *$ & $.24 *$ & $.20 *$ & $.29 *$ & .13 & .12 & - & & \\
\hline Self-talk & 3.04 & .87 & -.17 & -.12 & -.10 & -.03 & $.19 *$ & .11 & $.46 * *$ & .17 & $.22 *$ & .05 & .08 & .09 & .15 & - & \\
\hline Self-evaluation & 2.84 & 1.44 & -.13 & .03 & -.05 & .08 & .02 & -.04 & $.57 * *$ & .04 & .09 & .11 & .01 & .13 & .18 & .18 & - \\
\hline Work role innovation & 3.41 & .65 & -.10 & $.37 * *$ & .20 & .04 & $.27 * *$ & $.32 * *$ & $.37 * *$ & $.35^{* *}$ & $.26 * *$ & $.27 * *$ & $.29 * *$ & * $.25 *$ & $.21 *$ & .18 & .08 \\
\hline
\end{tabular}


Figure 2. Results of structural equation modelling: The final model with the standardized solution

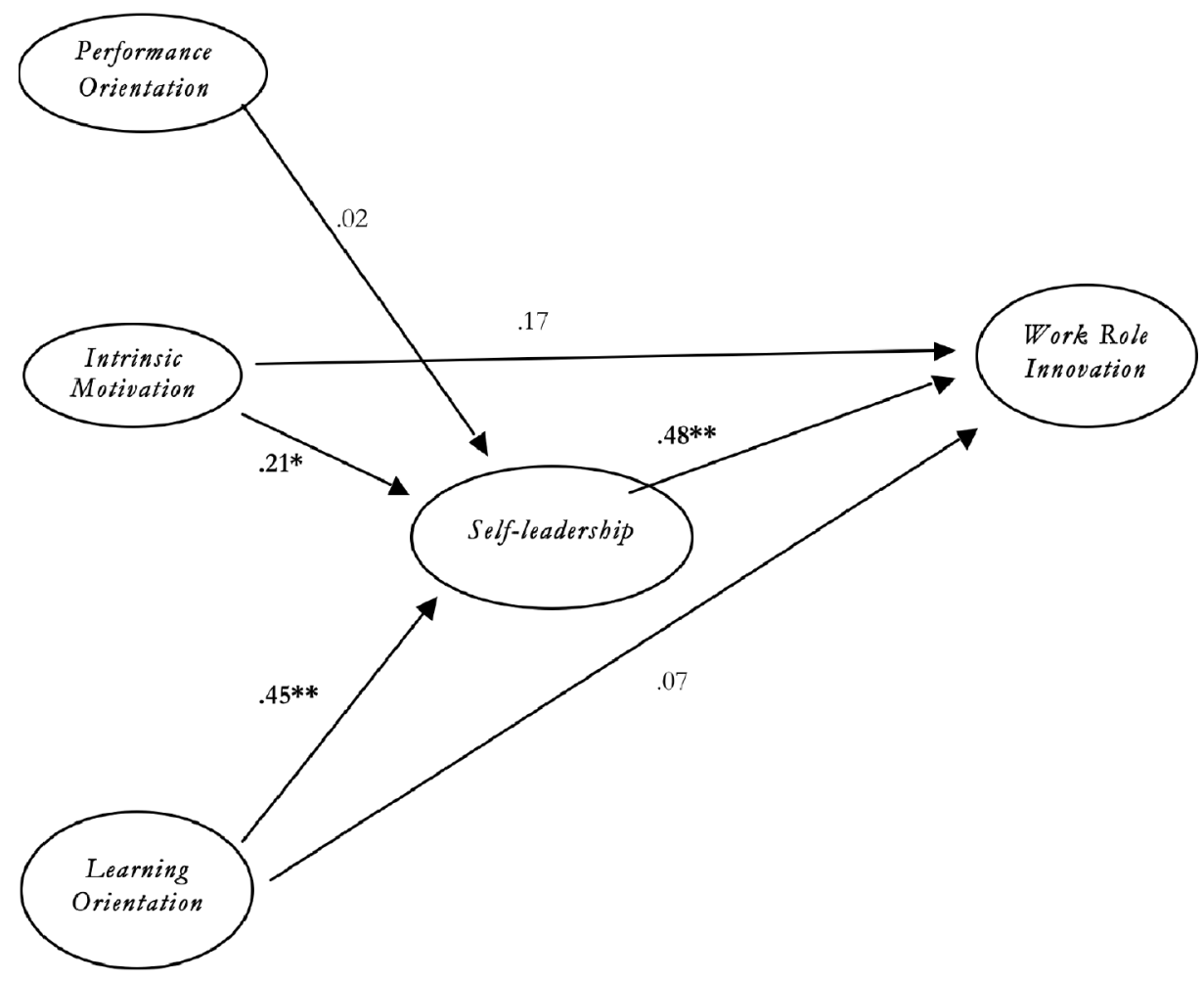

$* p<.05, * * p<.01$

role innovation was not supported, as the relationship between performance orientation and self-leadership was non significant, thus failing to support hypothesis 3. Intrinsic motivation predicted role innovation, and this relationship was mediated by self-leadership. A positive significant relationship between intrinsic motivation and self-leadership $(\beta=.25, p<.05)$ gives support to hypothesis 4 . Finally, with regards to the effect of the control variable, no significant effect was found between years of job experience and role innovation.

The above hypothesized model assumed full mediation of self-leadership between goal orientation and work role innovation and between intrinsic motivation and work role innovation. However, in order to verify that full mediation of self-leadership is the best fit to data when compared to alternative models, we compare our hypothesized model against a partially mediated alternative. In this model we added direct paths from intrinsic motivation and from learning orientation to role innovation. A direct path from performance orientation and role innovation was left out of this alternative model because we failed to find a significant correlation between these two latent variables. The alternative model of partial mediation of self-leadership did not provided a better fit to the data, $\chi^{2}=473.98, \chi^{2} / d f=1.27$, RMSEA $=.05, \mathrm{CFI}=.91$, and
$\mathrm{SRMS}=.09$. Although this model also provided a reasonably good fit to the data, the direct paths from intrinsic motivation and from learning goal orientation to work role innovation were not significant as shown in Figure 2.

\section{Discussion}

Although work role innovation is a well-documented topic, this research addresses new relations concerning self-leadership, intrinsic motivation and goal orientation strategies. The findings of this study contribute to the enrichment of the growing body of research on self-leadership, and helps to clarify the contribution of self navigation competences on the innovative behaviors of employees.. The full mediation effect of self-leadership between learning goal orientation and role innovation reinforces earlier propositions concerning the strong impact and relevance that self-leadership strategies have on the conduction and management of personal actions related to goal achievement (Houghton \& Neck, 2006; Manz, 1986; Neck \& Manz, 1992). These findings also support the existing knowledge about goal orientation strategies dependency on personal values and beliefs, being a predisposing trait in need of a driving capa- 
city to express itself and effectively impact on performance (Chen \& Mathieu, 2008; Smith \& Terry, 2003). The findings of this study also accentuate the idea that learning and performance orientation are distinct and even opposite dimensions of the some construct. The absence of relationship between performance orientation and role innovation is consistent with existing research, which found that performance oriented individuals, unlike learning oriented ones, perform poorer when facing complex and challenging tasks (LePine, 2005; VandeWalle et al., 1997). The preference of performance oriented individuals for simple and familiar tasks also helps explain why they seldom engage in self-leadership behaviors has found in our study (Button et al., 1996; VandeWalle et al., 1999)

Finally, our findings also allowed for the empirical validation of the theoretical proposition considering intrinsic motivation as an antecedent and necessary condition to self-leadership to happen (Neck \& Houghton, 2006). Intrinsically motivated individuals are more likely to prefer unstructured tasks and more willing to try to improve the way they work. In order to accomplish that will they need to develop behavioral strategies that facilitate the innovative venture. Therefore, is not unexpected that employees with higher intrinsic motivation look for new ways to do their job well.

Considering what has been found on goal orientation and intrinsic motivation, it is important to reinforce that goal orientation is all about the predisposition to act towards challenges and goals, according to certain scripts (Chen \& Mathieu, 2008). What this research as shown is that scripts and motivation on their own are not enough to generate controlled action towards goals and objectives. Indeed, they need selfleadership strategies and competences to effectively impact on work role innovation.

\section{Limitations and future research}

A limitation of this research is its cross-sectional design. Even though the direction of relationships tested in our model is consistent with previous literature, only a longitudinal design would establish the proper direction of causality between the variables we studied. Also, our model aimed to test a relation between several variables that are always changing. Because so, the results found are limited to a specific moment in time. Thus, a longitudinal analysis should be considered in future research.

Another limitation that is dependent on the design adopted is common method variance due to the fact that both predictor and criteria variables were assessed from the same source at the same time. Role innovation measures depend only on the employee perspective, lacking supervisor ratings for cross comparison (Scullen, Judge \& Mount, 2003). Some authors ho- wever found no significant differences between self and supervisor ratings of performance (Demerouti, Verbeke \& Bakker, 2005), while others argue that different sources assess different competences thus the differences in ratings (Viswesvaran, Ones \& Schmidt, 2005). We cannot rule out the possibility that common method variance has contributed to some of the relationships. However higher intercorrelations would be expected if common method bias was responsible for the results. In future studies a measure of supervisorrated innovative behavior would help clarify these relationships.

Although Konradt et al., (2008) conclusions concerning autonomy non mediating effect on the relation between self-leadership and performance, it would have been interesting to include both performance and autonomy on this research, to find if they would fit the data and interact with the considered variables. In fact, a) for innovation to happen it is necessary the existence of a promotional context, one allowing error management practices and that supports co-workers autonomous, proactive and creative behaviours (Neck, Nouri \& Godwin, 2003; Van Dyck, Frese, Baer, \& Sonnentag, 2005), and b) self-leadership, self-efficacy and intrinsic motivation have proved to be dependent on autonomy levels and leadership style (Deci \& Ryan, 1985; Dysvik \& Kuvväs, 2008; Yun et al., 2006).

\section{Summary and conclusions}

Nowadays, self-leadership has been gaining increased projection and academic significance, being considered in recruitment and selection processes, training programs, and research on entrepreneurship and organizational behaviour (Carmeli et al., 2006; Konradt, AndreBen \& Ellwart, 2008;; Manz \& Neck, 1996; Neck \& Houghton, 2006). Besides, given selfleadership characteristics, it would be interesting to analyse its impact on career management and occupational stress and well being.

Still on self-leadership, future research should clarify the interactions found on self-leadership and performance orientation, which might suggest that constructive though pattern strategies minimize performance orientation dysfunctional beliefs and its negative impact (Chen \& Mathieu, 2008).

Self-leadership, as it is measured these days, might not be the best tool to address the self-guidance navigation behavioural and cognitive mechanisms that are known to congregate on it. This is so, because discrepancies were found between the impact of self-leadership strategies on performance. For instance, while behaviour focused strategies have shown to be effective, constructive thought pattern strategies not always suggests clear or significant results. Even natural rewards strategies usually lead to negative or non-significant effects. 
Considering self-leadership as a leadership processes in it self, it is possible to think on emergent phenomenon depending on contingency factors and on how strong self-leadership is within each individual. This lead us to the proposition that future research should more actively look at self-leadership as an ever changing process that must be addressed through multilevel and longitudinal research designs.

Finally, the results and conclusions drawn from this research allowed for the clarification of previously theoretical propositions concerning self-leadership, intrinsic motivation and work role innovation, while making pace for the opening of new research topics and paths to travel and explore.

\section{References}

Amabile, T. M. (1988). A Model of creativity and innovation in organizations. In B. M. Staw \& L., L., Cummings (Eds.). Research in Organizational Behaviour Vol. 10 (pp. 123-167). Greenwich, CT: JAI Press.

Amabile, T.M. (1997). Motivating creativity in organizations: On doing what you love and loving what you do. California Management Review, 40, 39-58.

Bandura, A. (1986). Social foundations of thought and action: A social cognitive theory. Prentice Hall, Englewood, Cliffs, NJ.

Button, S.B., Mathieu, J.E. \& Zajac, D. (1996). Goal orientation in organizational research: A conceptual and empirical foundation. Organizational Behavior and Human Decision Processes, 67, 26-48.

Carmeli, A., Meitar, R., \& Weisberg, J. (2006). SelfLeadership skills and abilities. International Journal of ManPower, 27, 75-90.

Carver, C.S. \& Scheier, M.F. (1981). Attention and SelfRegulation: A control theory approach to human behavior. Springer-Verlag, New York, NY.

Carver, C.S. \& Scheier, M.F. (1998). On the SelfRegulation of behavior. Cambridge University Press, New York, NY.

Chen, G., \& Mathieu, J.E. (2008). Goal orientation dispositions and trajectories: The roles of supplementary and complementary situational inducements. Organizational Behavior and Human Decision Processes, 106, 21-38.

Costa, P.T. Jr \& McCrae, R.R. (1988). Personality in adulthood: a six-year longitudinal study of self-reports and spouse ratings on the NEO Personality I inventory. Journal of Personality and Social Psychology, 54, 85363.

Curral, L.A. (2005). Sharedness in work team innovation: A process model of team regulation. $\mathrm{PhD}$ Thesis. Lisbon: Portugal.

Deci, E.L., \& Ryan, R.M. (1985). Intrinsic motivation and self determination in human behavior. Plenum, New York, NY.

Demerouti, E., Verbeke, W. \& Bakker, A. (2005). Exploring the relationship between a multidimensional and multifaceted burnout concept and self-rated performance. Journal of Management, 31, 186-209.

DiLiello, T.C. \& Houghton, J.D. (2006). Maximizing leadership capacity for the future: Toward a model of SelfLeadership, Innovation and Creativity. Journal of Managerial Psychology, 21, 319-337.

Dweck, C.S. (1986). Motivational processes affecting learning. American Psychologist, 41, 1040-1048.

Dweck, C.S. \& Legget, E.L. (1988). A Social cognitive approach to motivation and personality. Psychological Review, 95, 256-273.

Dysvik, A. \& Kuvväs, B. (2008b). The relationship between perceived training opportunities, work motivation and work outcomes. International Journal of Training and Development, 12, 138-157.

Ford, M.E. (1992). Motivating humans: Goals, emotions and personal agency beliefs. Newbury Park, CA: Sage.

Giorgianna, S. (2007). Self-Leadership: A cross-cultural perspective. Journal of Managerial Psychology, 22, 569-589.

Gollwitzer, P.M., Heckhausen, H. \& Steller, B. (1990). Deliberative and implemental mind sets: Cognitive tuning toward congruous thoughts and information. Journal of Personality and Social Psychology, 59, 11191127.

Gollwitzer, P.M. (2003). Why we thought that action mind sets affects illusions of control. Psychological Inquiry, 14, 261-269.

Hirst, G., van Knippenberg, D., \& Zhou, J. (2009). A crosslevel perspective on employee creativity: Goal Orientation, team learning behaviour, and individual creativity. Academy of Management Journal, 52, 280293.

Houghton, J.D., \& Neck, C.P. (2002). The revised selfleadership questionnaire: Testing a hierarchical factor structure for Self-Leadership. Journal of Managerial Psychology, 17, 672-691.

Houghton, J.D., Bonham, T.W., Neck, C.P. \& Singh, K. (2004). The relationship between self-leadership and personality: a comparison of hierarchical factor structures. Journal of Managerial Psychology, 19, 427-41.

Hu, L.T. \& Bentler, P.M. (1999). Cutoff criteria for fit indexes in covariance structure analysis: Conventional criteria versus new alternatives. Structural Equation Modelling, 6, 1-55.

Judge, A.T., \& Piccolo, R.F. (2004). Transformational and transactional leadership: A Meta-analytic test of their relative validity. Journal of Applied Psychology, 89, 755-768.

Kanfer, R. (1988). When a thousand flowers bloom: Structural, collective and social conditions for innovation at work, In B.M. Staw \& L.L. Cummings (Eds.), Research in Organizational Behavior, Vol. 10 (pp. 169211). Greenwich, CT: JAI Press.

Kanfer, R. (1990). Motivation and individual differences in learning: An integration of developmental, differential and cognitive perspectives. Learning and Individual Differences, 2, 221-239. 
Konradt, U., Andreßen, P., \& Ellwart, T. (2009). SelfLeadership in organizational teams: A multilevel analysis of moderators and mediators. European Journal of Work and Organizational Psychology (first published online 2008, http://pdfserve.informaworld.com/ 656047_77838 4746_791062291.pdf).

Kuvväs, B . (2006a). Performance appraisal satisfaction and employee outcomes: Mediating and moderating roles of work motivation. International Journal of Human Resources Management, 17, 504-522.

Latham, G., \& Locke, E. (1991). Self-regulation trough goal setting. Organizational Behaviour and Human Decision Processes, 50, 212-572.

Latham, G. (2007). Work motivation. History, theory, research and practice. London, UK: Sage.

LePine, J., A. (2005). Adaptation of teams in response to unforeseen change: Effects of goal difficulty and team composition in terms of cognitive ability and goal orientation. Journal of Applied Psychology, 90, 1153-1167.

Lichtenstein, B., Uhl-Bien, M., Marion, R., Seers, A., Orton, J.D., \& Schreiber, C. (2006). Complexity leadership theory: An interactive perspective on leading in complex adaptive systems. $E: C O, 8,2-12$.

MacKinnon, D.P., Fairchild, A.J., \& Fritz, M.S. (2007). Mediation analysis. Annual Review of Psychology, 58, 593-614.

Manz, C.C., (1986). Self-Leadership: toward an expanded theory of self-influence processes in organizations. Academy of Management Review, 11, 585-600.

Manz, C.C., \& Neck, C.P. (1999). Mastering self-leadership: Empowering yourself for personal excellence (2nd ed). Upper Saddle River, NJ: Prentice-Hall

Manz, C.C \& Neck, C.P. (2004). Mastering self-leadership: Empowering your self for personal excellence $\left(3^{\text {rd }}\right.$ ed). New Jersey: Prentice Hall.

Manz, C.C., \& Sims, H.P., Jr. (1980). Self-management as a substitute for leadership: A social learning perspective. Academy of Management Review, 5, 361-7.

Manz, C.C., \& Sims, H.P., Jr (2001). New superleadership: Leading others to lead Themselves., San Francisco, CA: Berrett-Koehler.

Mitchell T.R., \& Daniels, D. (2003). Motivation. In W. Borman, D.R. Ilgen, \& R.J.

Klimosky (Eds.), Handbook of Psychology: Industrial and Organizational Psychology, Vol.12. New Jersey: John Wiley \& Sons, Inc.

Neck, C.P., \& Houghton, J.D. (2006). Two decades of SelfLeadership theory.and research: Past developments, present trends and future possibilities. Journal of Managerial Psychology, 21, 270-295.

Neck, C.P., \& Manz., C.C. (1992). Though SelfLeadership: The impact of self talk and mental imagery on performance. Journal of Organizational Behaviour, 12, 681-689.

Neubert, M.J., \& Wu, Ju-Chien, C. (2006). An investigation of the generalizability of Houghton and Neck revised Self-Leadership questionnaire to a Chinese context. Journal of Managerial Psychology, 21, 360-373.
Nyder, M., \& Swann Jr., W.B. (1976). When actions reflect attitudes: The politics of impression management. Journal of Personality and Social Psychology, 34, 10341042.

Pattal, E.A., Cooper, H., \& Robinson, J.C. (2008). The effects of choice on Intrinsic Motivation and related outcomes: A meta-analysis of research findings. Psychological Bulletin, 134, 270-300.

Phelan, S., \& Young, A.M. (2003). Understanding creativity in the workplace: An examination of individual styles and training in relation to creative confidence and creative Self-Leadership. Journal of Creative Behaviour, 37, 266-281.

Schmitt, M.T., \& Branscombe, N.R. (2002). The meaning and consequences of perceived descrimination: Testes of significance and descriptive goodness-of-fit measures. Methods of Psychological Research Online, 8, 2374.

Scott, S.G., \& Bruce, R.A. (1994). Determinants of innovative behaviour: A path model of individual innovation in the workplace. Academy of Management Journal, 37, 580-607.

Scullen, S.E., Mount, M.K. \& Judge, T.A. (2003). Evidence of the construct validity of developmental ratings of managerial performance. Journal of Applied Psychology, 88, 50-66.

Seligman, M.E.P. (1991). Learned optimism. New York: Alfred A. Knopf.

Shalley, C.F., Zhou, J., \& Oldham, G.R. (2004). The effects of personal and contextual characteristics on creativity: Where should we go from Here? Journal of Management, 30, 933-958.

Smith, J.A., \& Terry, D.J. (2003). Attitude-behaviour consistency: the role of group norms, attitude accessibility, and mode behavioural decision making. European Journal of Social Psychology, 33, 591-608.

Stewart, G.L., Carson, K.P., \& Cardy, R.L. (1996). The joint effects of conscientiousness and self-leadership training on self-directed behavior in a service setting. Personnel Psychology, 49, 143-64.

Van de Ven, A.H. (1986). Central problemms in the management of innovation. Management Science, 32, 590608.

VandeWalle, D., Brown, S.P., Cron, W.L., \& Slocum, J.W. (1999). The influence of goal orientation and self-regulation on sales performance: A longitudinal field test. Journal of Applied Psychology, 84, 249-259.

VandeWalle, D., \& Cummings, L.L. (1997). A test of the influence of goal orientation in the feedback seeking process. Journal of Applied Psychology, 82, 390-400.

Van Dyck, C., Frese, M., Baer, M., \& Sonnentag, S. (2005). Organizational error management culture and its impact on performance: A Two-Study replication. Journal of Applied Psychology, 90, 1228-1240.

Vargas, R. (2007a). A arte de tornar-se inútil: Desenvolvendo líderes para vencer desafios $\left(5^{a} e d\right)$. Lisboa: Gradiva.

Viswesvaran, C., Schmidt, F.L. \& Ones, D.S. (2005). Is there 
a general factor in ratings of job performance? A metaanalytic framework for disentangling substantive and error influences. Journal of Applied Psychology, 90, 108131.

West, M.A., Shackleton, V.J., Hardy., G.E \& Dawson, J.F. (2001). Work role characteristics, job security and individual innovation at work. Unpublished manuscript, ABS, Birmingham, UK.
Williams, R.L., Verble, J.S., Price, D.E., \& Layne, B. H. (1995). Relationship of self-management to personality types and indices. Journal of Personality Assessment, 64, 494-506.

Yun, S., Cox, J., \& Sims Jr. H.P. (2006). The forgotten follower: A contingency model of leadership and follower self-leadership. Journal of Managerial Psychology, 21, 374-388.

Manuscrito Recibido 15/06/2009

Revisión Recibida 20/07/2009

Aceptado: 20/07/2009 